\section{eOrganic: The Organic Agriculture Community of Practice for eXtension}

\author{
Alexandra G. Stone ${ }^{1,6}$, Danielle D. Treadwell ${ }^{2}$, Alice K. Formiga ${ }^{1}$, \\ John P.G. McQueen ${ }^{1}$, Michelle M. Wander ${ }^{3}$, James Riddle ${ }^{4}$, \\ Heather M. Darby ${ }^{5}$, and Debra Heleba ${ }^{5}$
}

\begin{abstract}
AdDitional INDEX wORDs. distance education, extension, collaborative learning, organic farming, online learning, website, webinar, Web 2.0
\end{abstract}

\begin{abstract}
SUMMARY. eOrganic is the organic agriculture community of practice (CoP) and resource area for eXtension. eOrganic's primary community of interest (CoI) is organic farmers and the agricultural professionals who support them. The $\mathbf{2 5 0}$ members of the eOrganic CoP include farmers, researchers, certifiers, and extension/other agricultural professionals. eOrganic's mission is to build a diverse national CoP and use web technologies to synthesize existing information, emerging science, and practical knowledge into information resources and training materials for its CoI. eOrganic strategies to achieve that mission include collaborative publication, stakeholder engagement, community development, project management, evaluation, and fundraising. eOrganic's public site currently offers 240 articles, 250 videos, 80 webinars and broadcasts, and 100 frequently asked questions (FAQs). eOrganic CoP members have answered more than 1000 "Ask an Expert" questions. eOrganic authors collaboratively develop articles in eOrganic's collaborative workspace, which undergo review by two anonymous reviewers and National Organic Program (NOP) compliance review. eOrganic will offer online courses in 2012. eOrganic stakeholders evaluated eOrganic articles and videos in 2010 and overall they stated that they were relevant, science-based, and useful. Three quarters of webinar and broadcast participants said the webinar improved their understanding of the topic, and $83 \%$ said they would recommend the webinar to others. Sixty-nine percent of webinar survey respondents stated that they changed practices or provided others with information as the result of the webinar. eOrganic surveyed active CoP members in 2011. Members view eOrganic as important because it is the only national organic agriculture resource with direct ties to university research and they considered all of eOrganic's core activities important. eOrganic is supported by small grants from eXtension and subawards in more than 20 U.S. Department of Agriculture (USDA), National Institute of Food and Agriculture (NIFA) research/extension projects. To enhance its financial sustainability, eOrganic will work to solidify its partnership with NIFA programs and diversify its funding sources to include course fees and underwriters.
\end{abstract}

$C_{\text {t }}$ Organic is the organic agriculture CoP and resource area for the national web-based extension

This paper was part of the workshop "The Growing Involvement of Horticulture in eXtension: Updates and Opportunities" held 27 Sept. 2011 at the ASHS Conference, Waikoloa, HI, and sponsored by the eXtension (EEXT) Working Group.

${ }^{1}$ Department of Horticulture, Oregon State University, 4017 ALS, Corvallis, OR 97330

${ }^{2}$ Department of Horticultural Sciences, University of Florida, 1143 Fifield Hall, P.O. Box 110690, Gainesville, FL 32611

${ }^{3}$ Department of Natural Resources and Environmental Sciences, University of Illinois, 1102 South Goodwin Avenue, Urbana, IL 61801

${ }^{4}$ Southwest Research and Outreach Center, University of Minnesota, 23669 130th Street, Lamberton, MN 56152

${ }^{5}$ University of Vermont Extension, 278 S. Main Street, St. Albans, VT 05478

${ }^{6}$ Corresponding author. E-mail: stonea@hort. oregonstate.edu. community of land-grant university content providers, eXtension. eOrganic was initiated as a CoP in 2007 (the first eXtension CoPs were initiated in 2006) and launched its first content in Jan. 2009. The eOrganic CoP includes farmers, researchers, educators, certifiers, as well as extension personnel and other agricultural professionals. eOrganic considers its primary CoI (public content users, or stakeholders) to be organic farmers and other farmers interested in organic agricultural information, as well as the agricultural professionals (including extension professionals) and technical service providers who work with them.

Demand for science-based information about organic agriculture increased in the United States after the establishment of a federally regulated definition of organic agriculture and subsequent passage of the Organic Foods Production Act in 1990 (Organic Foods Production Act, 1990). Sales of organic products surged after the NOP was fully implemented in 2002 , creating an urgent need for the type of reliable, science-based agricultural information that extension is known for (Agunga and Idogan, 2007; Boone et al., 2007; Middendorf, 2007; Thilmany, 2006). Filling this information gap proved to be a challenge for researchers and extension specialists because federal investment in organic farming research was very limited at that time. Driven by the emerging need for science-based information on organic farming systems management, the USDA-NIFA Organic Research and Extension Initiative (OREI) and Organic Transitions (ORG) competitive grant programs were initiated in 2002. However, long-term systems research projects investigating soil and pest ecology or carbon sequestration take many years to deliver results, and results often take three to five years to appear in peer-refereed journals. As a result, only a limited amount of organic systems management research data has been available from these programs to date. In addition, much of the knowledge about how to manage complex organic agroecosystems resides with experienced organic farmers. It was clear to eOrganic members that science-, practice- and regulation-based organic agriculture information must be aggregated and integrated to most rapidly produce information of the greatest utility to farmers and industry.

eOrganic's mission has been to fill this information gap by building a diverse national $\mathrm{CoP}$ and using web technologies to synthesize existing information, emerging science, and practical knowledge into information resources and training materials for organic farmers and the professionals who support them. eOrganic's approach to achieving this mission can be organized into six primary areas:

1) Collaborative publication. Supporting collaborative development and publication of peer-reviewed articles, FAQs, and videos;

2) Stakeholder engagement. Facilitating engagement of farmers and agricultural professionals through webinars, broadcasts, short courses, "Ask an Expert," and other interactive tools; 
3) Community development. Convening a national web community of researchers, agricultural professionals, farmers, and certifiers at eOrganic's collaborative workspace to facilitate networking and colearning;

4) Project management. Facilitating organic research/outreach project management;

5) Evaluation. Evaluating utility and impact of eOrganic;

6) Financial stability. Fundraising to support eOrganic core operations.

The purpose of this article is to summarize eOrganic's development, successes, and challenges through the course of its first five years as an eXtension CoP.

\section{Collaborative publication}

eOrganic strives to provide content that is science-, experience-, and regulation-based. To this end, eOrganic seeks content from the following sources:

- Information derived primarily from conventional production systems relevant to organic systems (as in Gamroth, 2009; Phillips, 2009).

- Management information derived from organic systems research which has not yet been interpreted for on-farm application as available from organic systems trials and on-farm and other research projects (as in Eastburn, 2009; USDA, 2011).

- Management information derived from farmer experience (as in Stone, 2006; Weston et al., 2009).

- Regulation-based information derived from the NOP and other regulations (as in Andrews and Baker, 2009).

eOrganic's public site, the organic agriculture resource area at eXtension, currently offers articles, videos, webinars, broadcasts, and FAQs. eOrganic authors collaboratively develop articles in eOrganic's collaborative workspace. All articles are subject to a review process developed by the eOrganic leadership team and eOrganic members during 2007-09. Highlights of the process include review by two anonymous reviewers as well as a review to ensure that content is compliant with the code of federal regulation of the NOP. eOrganic's review process is followed by copy editing and publication to eXtension. Information on how to publish all content types is available in the Help section of eOrganic's collaborative workspace.
eOrganic staff members support authors in learning how to use the collaborative workspace and developing and publishing various content types; they also coordinate peer and NOP compliance review of articles, videos, and course materials.

eOrganic will offer online courses in 2012, including two courses on organic dairy production and an organic seed production course, through eXtension's Moodle (Perth, Australia) campus. Moodle is a free, open-source web application designed to create web-based courses that support collaborative and interactive learning environments. Moodle boasts over six million courses and 60 million registered users globally (Moodle, 2012). eOrganic is working to facilitate video production by its members. eOrganic staff taught a video capture course using Moodle during Winter 201112 to 15 eOrganic research/outreach project group members and the curriculum is publicly available at the eXtension Moodle campus. The course walks students through audience identification, storyboarding, production planning, and video and audio capture. eOrganic video staff edit video, still photos, and audio into video clips, which are published to eOrganic's YouTube (San Bruno, CA) site after undergoing eOrganic's peer and NOP compliance review processes.

eOrganic has published more than 240 articles and 100 FAQs. Video clips (not webinars or broadcasts) are also available with transcription at eXtension. eOrganic's pages at eXtension have been viewed over one million times by over 450,000 unique visitors from Apr. 2009 to May 2012. In Jan. to Mar. 2012, eOrganic's monthly page views averaged more than 40,000. eOrganic's 247 videos (video clips, webinars, and broadcasts) are available at the eOrganic YouTube channel, which has more than 1100 subscribers and 845,000 video views since its initiation in Aug. 2008.

\section{Stakeholder engagement}

eOrganic actively engages its stakeholders at its public site through Ask an Expert, the interactive question and answering platform supported by eXtension. Site users submit a question (and may submit a photo) to eXtension, and organic farming questions are routed by the system and/or by eOrganic staff to someone with the appropriate expertise; the responding expert submits an answer into the system, and the system e-mails the answer to the person who asked the question. Frequently, this exchange leads to additional information exchange outside of the eXtension system if both parties agree to be contacted outside of eXtension. For example, a Florida producer with a question about organic greenhouse certification asked a question that was directed to and answered by a University of Florida extension specialist; the two then followed up with a phone call to further discuss the farmer's questions. These types of exchanges made possible by the eXtension initiative strengthen the linkages between farmers and landgrant university experts both nationally and locally. As of May 2012, the eOrganic community has answered more than 1000 organic farming questions through the eXtension Ask an Expert system.

eOrganic also interacts with the public through its webinars. Typically, participants type questions into the system for the presenter, which are then read aloud by the webinar moderator and answered aloud by the presenter. In some webinars, electronic polls are used to query the webinar audience during the webinar. eOrganic sends evaluation surveys to all participants following each webinar. eOrganic's webinar series has evolved into its most effective engagement strategy. eOrganic hosted 78 webinars and individual conference broadcast sessions from Dec. 2009 through Mar. 2012, with a total number of 7608 attendees ( 6605 webinar participants and 1003 broadcast participants). Mean webinar attendance increased from 87 attendees in 2010 to 143 in 2012. Across all webinars, webinar participants describe themselves as farmers $(29 \%)$, extension professionals (12\%), university researchers or educators (11\%), agricultural professionals (20\%), and others such as organic certifiers, government agency researchers and staff, nonprofit organization staff, and Master Gardeners from throughout the United States and other countries (28\%). eOrganic broadcasted presentations from five conferences in 2011 and 2012, averaging 167 virtual attendees per conference. The reach of the webinars and broadcasts has increased dramatically over the past year now that they are all 
available at eOrganic's YouTube site; views of those archived webinars increased from 5800 in Apr. 2011 to 42,500 in May 2012 (Formiga et al., 2012). eOrganic also engages its stakeholders at booths at in-person organic farming conferences and through its Facebook (Menlo Park, CA) and Twitter (San Francisco, CA) sites. eOrganic's Facebook site has more than 1000 fans and its Twitter account has more than 1200 followers.

\section{Community development}

As eOrganic worked to generate content during and after its public content launch in Jan. 2009, the leadership team realized that engagement with a large group of people with varied organic agriculture expertise from across the United States was necessary to develop a credible national organic agriculture information service. In addition, the leadership team realized that the collaborative workspace, developed initially solely for publication collaboration and support, could be used to convene and support an organic agriculture web community. People interested in becoming members of the eOrganic CoP were asked to demonstrate interest and experience in organic farming systems through a simple application process. Upon membership, participants gained access to the collaborative workspace and received eOrganic's CoP newsletter. In the workspace, members used their personal profiles to describe themselves and their expertise and interests, used the site to learn about their peers and identify collaborators, joined and created groups that were working on a specific project or topic, and learned about other projects and groups by reading materials that were viewable to all eOrganic members. The flexibility of the workspace allowed groups to work privately on materials considered intellectual property such as data sets, articles, or proposals, while sharing information about their project such as reports, publications, and research protocols with all workspace members.

eOrganic's collaborative workspace currently has 961 members including $\approx 76$ farmers; 112 extension professionals; 509 university researchers, educators, or students; 92 government agency staff; 43 certification agency staff; 64 nonprofit agency staff; and 64 other agricultural professionals. Of this large community in eOrganic.info, more than 250 people have actively contributed to eOrganic in some fashion, from providing leadership (18), to authoring articles $(90+)$, to peer-reviewing articles and videos $(80+)$, to presenting webinars and broadcasts $(170+)$, to answering organic agriculture Ask an Expert questions (177); these 250 would be considered to be eOrganic's active CoP. eOrganic CoP members have coordinated at least five virtual brown bag discussions, two of which have led to new collaborations including the development of NIFA integrated project proposals. Thematic webinar series have been coordinated on topics including dairy production, climate change, cover cropping, and reduced tillage, one goal of which is to foster colearning amongst research/ outreach groups and individuals.

\section{Project management}

One of eOrganic's goals is to rapidly deliver organic agriculture research results to farmers and agricultural professionals. One idea for facilitating this is to provide research project/group management and communication tools, as well as eXtension content development tools, all in one group workspace in eOrganic's larger collaborative workspace. Groups use tools such as member lists (linking to member personal profiles), group pages (for meeting minutes and research protocols), eXtension/ eOrganic publication information (to publish articles, webinars, and videos to eXtension/eOrganic), file sharing (for proposals, protocols, publications, and presentations), discussion forums (for decision making), photo sharing, news, events, and activity dashboards. Project groups aggregate photos, proposals, reports, and other project-related information in their workspace so all the materials required to develop an eOrganic article or webinar are readily available to anyone in the group, facilitating and expediting content development. In addition, eOrganic offers web conferencing, training on the use of eOrganic.info and publication to eXtension, video capture training, video editing, and support for Moodle course development to research/outreach groups. eOrganic is also supporting simple public websites (also managed through the same group workspace) for project groups who have included eOrganic in grant proposals, and is developing more complex websites for an additional fee.

There are currently 21 research / outreach project groups in eOrganic. info that are using a project workspace to some degree; six are using their project workspaces extensively. eOrganic staff and leadership team groups also extensively use their group workspaces. A multi-institution research/ outreach project group $(20+$ members) has reported that its workspace is critical to their coordination of their project. eOrganic has also developed a public website, including an interactive variety trialing database, for that project.

\section{Evaluation}

The eOrganic leadership team, members, and staff have solicited feedback from each other as well as other members and users of the public eXtension/organic agriculture site through a variety of mechanisms, including formal evaluation administered via online surveys, face-to-face meetings, and conference calls where self-evaluation was an objective, and informal feedback solicited from our stakeholder advisory board, CoP members, and end users of eOrganic products. All evaluation protocols were reviewed and approved by the Oregon State University Institutional Review Board. Significant evaluation activities are summarized below.

Evaluation OF eOrganic ARTICLES AND VIDEOS. eOrganic stakeholders evaluated eOrganic articles and videos for content quality, relevance, and readability in Winter 2010-11 (Formiga et al., 2011). One hundred eighty-six experienced organic farmers and research/extension professionals with organic expertise from across the country were asked to participate in the evaluation process, and 144 completed reviews were submitted. Reviews were anonymous, so some reviewers may have submitted more than one review. Reviewers identified themselves as farmers (36\%), certifiers $(1 \%)$, researchers $(15 \%)$, extension professionals (31\%), and other (agency and nonprofit staff, organic inspector, consultant; 16\%). The mean years of agricultural and organic agricultural experience of the reviewers were 24.6 and 12.6 years, respectively. 
The farmer and agricultural professional reviewers of eOrganic's articles and videos considered them to be relevant, science-based, and useful. Ninety-two percent of survey respondents agreed that the article or video was very relevant to important farming problems or issues, $73 \%$ agreed that "the information presented was supported by scientific evidence," $84 \%$ agreed that the article or video was "useful and practical and could be applied in real farming practice," and $74 \%$ "would recommend this article or video to others who had questions about this topic" (Formiga et al., 2011).

Evaluation of eOrganic webinars. Participants in eOrganic webinars and conference broadcasts have been asked since Dec. 2010 to complete an online evaluation sent to them by e-mail immediately following the webinar or conference presentation to evaluate their perceptions of the educational value, utility, technical level, and accessibility of webinars, as well as whether they would recommend them to others (Formiga et al., 2011, 2012). Participants were also asked to recommend future topics and comment on how the webinars could be improved. The average response rate to evaluations immediately following the broadcast was 63\%. Across all immediate feedback survey respondents, $75 \%$ said the webinar improved their understanding of the topic and $78 \%$ said they would apply the knowledge gained; $83 \%$ said they would recommend the webinar to others. Only $4 \%$ of respondents said they had difficulty accessing the webinar or broadcast.

eOrganic sent an impact evaluation survey to all participants of 16 webinars 6 to 18 months after the webinars were broadcast (Formiga et al., 2011, 2012). The survey asked participants to identify which of their practices (if practitioners) or recommendations (if agricultural professionals making recommendations to practitioners) changed as the result of attending the webinars. Out of 691 total respondents to the impact surveys, 69\% (almost equally divided between farmers and agricultural professionals) responded that they had changed practices or provided others with information, or were better able to communicate with farmers about the topic as a result of the webinar.
Evaluation data on changes in practices as a result of a webinar on tomato (Solanum lycopersicum) grafting (Formiga et al., 2011; Louws and Rivard, 2011) is presented as an example below. Sixty-nine percent of farmer respondents said that the webinar contributed to changes in their farming practices and $84 \%$ of all respondents said they applied the knowledge gained in this webinar to their work. Forty-eight farmers stated that they changed the following practices as a result of the webinar; 21 (44\%) grafted tomatoes on their farm, $34(71 \%)$ learned how to graft tomatoes, $26(54 \%)$ purchased grafting supplies, $17(35 \%)$ installed a heating chamber, $10(21 \%)$ experienced greater yields as a result of grafting, $10(21 \%)$ increased profits as a result of grafting, and four $(8 \%)$ grafted other crops. Thirty-five farmer advisers provided information on the following as a result of the webinar; 25 (71\%) provided information on the benefits of grafting, $24(69 \%)$ provided information on how to graft tomatoes, $21(60 \%)$ provided information on supplies needed for grafting, 16 (46\%) provided information on how to find rootstocks for grafting, 15 (43\%) provided information on how to find grafting supplies, and three (9\%) provided farmers with other advice based on what they learned at the webinar.

Evaluation of eOrganic by active CoP members. With support from the Institute for Conservation Leadership (Tacoma Park, MD), eOrganic surveyed 189 active members (members who had contributed to eOrganic as leaders, authors, reviewers, Ask an Expert responders, presenters) in Fall 2011 (Wander et al., 2011). The objectives of the survey were to assess member use and perceived value of eOrganic's core operations, describe eOrganic's role in the larger organic community, and identify current and future membership needs. Questions focused on eOrganic's expressed goals: engaging farmers, agricultural professionals, and other members of the organic agriculture community with timely and relevant science-, experience-, and regulation-based information; facilitating project management, communication, and publication to eXtension; and fostering a national organic research and outreach community. The survey consisted of 25 questions in several formats (short-answer, ranking, and yes /no). Fifty-five members $(29 \%)$ responded. The survey results were compiled and discussed by eOrganic leadership team members and staff at a planning meeting in Winter 2011.

Most CoP member respondents stated they have been eOrganic members since eOrganic's inception in 2009 , although $25 \%$ of respondents stated they joined in 2010 or later. All respondents stated they have participated as authors and/or reviewers of content published in one or more of eOrganic's publication outlets including eXtension and YouTube. Nearly $30 \%$ of respondents had presented a webinar, 30\% responded to an Ask an Expert question, and 31\% maintained active participation in an eOrganic. info group. However, 26\% of respondents stated they were members of a group but were not active. Thirtyeight percent of members were involved in eOrganic activities at least once per month, 36\% were active every few months, and $24 \%$ participated twice per year or less.

Members were asked to rank (from essential to not important) eight eOrganic activities that together comprise the majority of eOrganic's effort. Fifty-four percent of respondents ranked two eOrganic activities as essential or very important: connecting a national community of organic professionals (farmers, certifiers, researchers, extension, etc.) at eOrganic's collaborative workspace, and facilitating engagement among farmers and organic professionals through webinars. When asked if those same two activities were important to eOrganic's future success, essential and very important responses increased for both activities $(74 \%)$. Collaborative development of peer-reviewed articles for eXtension was ranked important or greater by $69 \%$ of respondents, followed by video production (65\%). Seventy-six percent of respondents believed articles and videos were important to eOrganic's future. Participation in the Ask an Expert feature of eXtension was ranked important or greater by the majority of respondents but to a lesser degree than other activities. Only one activity was ranked not important by a significant number of respondents (27\%): facilitating project management, networking, and colearning in the collaborative 
workspace. This activity was ranked lowest in terms of current benefit, but increased in importance in the future; $80 \%$ of respondents believed that activity to be important to essential to eOrganic's future success.

eOrganic was viewed by members as important because it is the only national organic agriculture resource with direct ties to university research. Members felt that the information on the site was credible and that eOrganic's relationship with eXtension provides eOrganic with credibility and visibility. They felt that the technology services eOrganic provides to research and outreach groups are valuable and that it was a strength that eOrganic offered multiple functions and services under one umbrella. They appreciated the opportunity to interact with farmers and researchers from other states, that the resources were free to end users, and that farmers were often involved in content generation.

Most members indicated they would continue to maintain or increase their current level of commitment to eOrganic in the next three to five years, and many offered suggestions for how to improve their working relationship with eOrganic. The most frequent suggestion was that eOrganic should help them integrate their local and regional research and extension efforts into eOrganic programming. Lack of funding was an issue for some members who had difficulty volunteering time; however, others felt that collaborative fundraising with eOrganic was an opportunity to support new resource development. Several members stated that if eOrganic made available stakeholder usage data for eOrganic educational products they could better justify their time spent working with eOrganic. Additional suggestions included increasing visibility and recognition of volunteers for their contributions and broadly communicating eOrganic's needs to the membership; some members stated that they were willing to dedicate time to complete a task, and simply needed to be asked. The peer-review process was seen by some as cumbersome, but others commented that the editorial standards and process improved content quality. Research and outreach group workspaces were considered valuable, but there were requests to make the workspaces more userfriendly and to provide text- and video-based how-to resources so members could more easily learn how to use the workspaces. Members also made suggestions for new or enhanced eOrganic functions, including improving access from mobile devices and developing short courses for specific sectors (e.g., organic certification staff).

Members were asked to describe a vision for and obstacles to eOrganic's success over the next five years. Overall, members felt that eOrganic's current mission and goals would remain relevant over the next five years. Members listed 1) lack of time for volunteer contributions, 2) a need for more eOrganic support staff, 3 ) a need for more technically advanced content, and 4) a need to secure stable funding for eOrganic core operations as the most important obstacles to eOrganic's future success.

\section{Financial stability}

eOrganic is supported by the efforts of many volunteers as well as its seven part-time staff located at University of Vermont, University of Illinois, University of Minnesota, and Oregon State University. These staff have been and continue to be critical to eOrganic's success as they l) support the eOrganic collaborative workspace and its feed to eXtension, as well as eOrganic's YouTube site; 2) support CoP members and projects in use of the workspace, video production, and Moodle course development; 3 ) manage the editorial process; 4) coordinate Ask an Expert; 5 ) coordinate and support the webinars and broadcasts; and 6 ) reach out to stakeholders and CoP members through the eOrganic newsletter and social media. Staff support is by far the largest item in eOrganic's operating budget, which also includes funds for travel (primarily to organic farming, professional society, and eXtension conferences, and to convene the leadership team and content development groups) and materials and supplies (such as banners, bookmarks and other outreach materials, as well as communication supplies and software licenses).

eOrganic received two grants from NIFA OREI and annual small grants from eXtension that together covered its core operating expenses from its inception in 2007 through 2011 . eOrganic is now supported by subawards in more than 20 NIFA (primarily OREI and ORG) integrated research/extension projects that included eOrganic in their plans of work and budgets.

\section{Looking forward}

eOrganic evolved during the past five years from a handful of leadership team members into a national web community almost 1000 strong with a growing national and international audience of more than 500,000. eOrganic started by publishing articles, FAQs, and videos and then diversified into producing webinars and broadcasts and supporting research/ outreach project management and community networking. This growth and development was likely due to the combination of a critical need for weband science-based information on organic farming, a strong and creative leadership team, talented staff, a committed and productive $\mathrm{CoP}$, and financial support from eXtension and NIFA.

As research and extension dollars are reduced nationwide, and stakeholders increasingly look to the web for credible science-based information, answers, and engagement, eOrganic and other national coordinated and interactive research/ outreach websites will become increasingly critical to the success of land-grant universities and extension. However, despite its successes, eOrganic faces many challenges, including the scarcity of $\mathrm{CoP}$ member time, a need for more staff, and consistent funding. eOrganic will continue to work to improve member services and support so members can gain more recognition for and document impact of their volunteer contributions in an effort to increase volunteer participation. To enhance its financial sustainability, eOrganic will work to solidify its partnership with NIFA organic farming and other programs and diversify its funding sources to include course fees and underwriters.

\section{Literature cited}

Agunga, R. and C. Idogan. 2007. Organic farmers' need for and attitudes towards extension. J. Ext. 45(4). 24 July 2012. <http://www.joe.org/joe/ 2007 december/a6.php>.

Andrews, N. and B. Baker. 2009. Can I use this input on my organic farm? 24 July 
2012. <http://www.extension.org/ pages/18321 $>$.

Boone, H.N., E.M. Hersman, D.A. Boone, and S.A. Gartin. 2007. Knowledge of sustainable agriculture practices by extension agents in Ohio, Pennsylvania, and West Virginia. J. Ext. 45(5). 24 July 2012. <http://www.joe.org/joe/ 2007october/rb2.php>.

Eastburn, D. 2009. Managing disease by managing soils. 24 July 2012. <www. extension.org/article/18638>.

Formiga, A.K., A.G. Stone, and J.P.G. McQueen. 2012. 2011-12 eOrganic webinar evaluation report. 24 July 2012. <http://eOrganic.info/evaluation>.

Formiga, A.K., A.G. Stone, J.P.G. McQueen, and M. Coe. 2011. 2009-11 eOrganic evaluation report. 24 July 2012. $<$ http://eOrganic.info/evaluation>.

Gamroth, M. 2009. Developing a grazing system for your organic farm. 24 July 2012. <http://www.extension.org/ pages/18345>.
Louws, F. and C. Rivard. 2011. Grafting for disease management in organic tomato production. 24 July 2012. <http:// www.extension.org/pages/32969>.

Middendorf, G. 2007. Challenges and information needs of organic growers and retailers. J. Ext. 45(4). 24 July 2012. <http://www.joe.org/joe/2007august/ a7.php>.

Moodle. 2012. Statistics. 24 July 2012. <http://moodle.org/stats>.

Organic Foods Production Act. 1990. Title 21 of P.L. 101-624 of the Food, Agriculture, Conservation, and Trade Act of 1990. 24 July 2012. <http:// www.law.cornell.edu/uscode/text/7/ chapter-94>.

Phillips, E. 2009. Conventional soil testing in organic farming systems. 24 July 2012. <http://www.extension.org/ pages/18566>.

Stone, A.G. 2006. Living mulch system: Introduction. Weed 'em and reap Part 2.
24 July 2012. <http://www.extension. org/pages/18414>.

Thilmany, D. 2006. The U.S. organic industry: Important trends and emerging issues for the USDA. 24 July 2012. <http://dare.colostate.edu/pubs/AMR/ AMR\%2006-01.pdf>.

U.S. Department of Agriculture. 2011. Organic farming systems research symposium. 24 July 2012. <http://www. extension.org/pages/33545>.

Wander, M., D.D. Treadwell, and J.P.G. McQueen. 2011. eOrganic Community of Practice member survey 2011. 24 July 2012. <http://eorganic.info/member survey2011>.

Weston, G., J. Eveland, J. Jebbia, and A.G. Stone. 2009. Incorporating high tunnels into a diversified organic vegetable farm in Oregon: Case study of Gathering Together Farm. 24 July 2012. <http:// www.extension.org/pages/18352>. 